

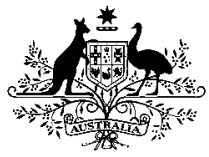

Australian Government

Australian Institute of Health and Welfare

Australian Institute of Family Studies

\section{Closing the gap}

\section{Supporting healthy communities through arts programs}

\section{Resource sheet no. 28 produced for the Closing the Gap Clearinghouse}

Vicki-Ann Ware

January 2014

\section{Summary}

\section{What we know}

- There are some evaluations, critical descriptions of programs and systematic reviews on the benefits to Aboriginal and Torres Strait Islander communities from participation in arts programs. These include: improved physical and mental health and wellbeing; increased social inclusion and cohesion; some improvements in school retention and attitudes towards learning; increased validation of, and connection to, culture; improved social and cognitive skills; and some evidence of crime reduction.

- The effects of arts programs can be powerful and transformative. However, these effects tend to be indirect. For example, using these programs to reduce juvenile anti-social behaviour largely work through diversion: providing alternative safe opportunities to risk taking, maintenance of social status, as well as opportunities to build healthy relationships with Elders and links with culture.

- Art forms such as song, dance and painting, coupled with ceremony, are integral to cultural continuity and cultural maintenance in Indigenous Australian communities.

\section{What works}

In the absence of strong evaluation evidence, below is a list of principles of 'what works' and 'what doesn't work' to assist with program design and implementation:

- Where no activity was previously made available, offering some type of art program to fill that void should be given priority over selectivity regarding which type of program to implement.

- Providing a quality artistic experience heightens engagement in the arts activity. 






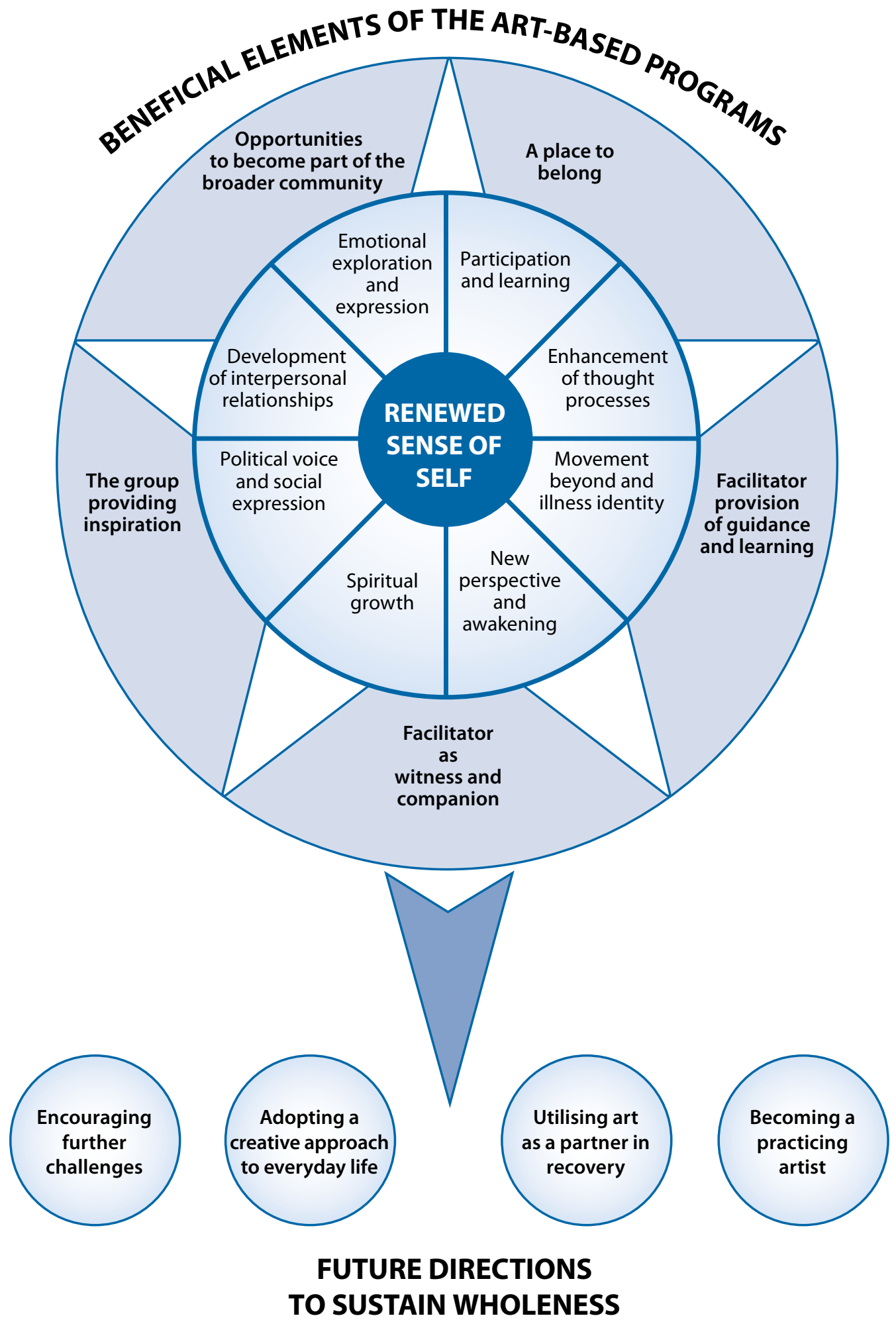

Source: Van Lith et al. 2009

Figure 1: Beneficial elements of the arts-based program 



3. Fostering intercultural exchange can help to build greater social cohesion: The evidence shows that festivals and other arts events (particularly those that conduct performance tours) can foster intercultural exchange. This can occur between different Indigenous groups (Palmer 2010; Phipps \& Slater 2010), and can also occur between Indigenous and non-Indigenous groups (Higgins 2005; MacDowell et al. 2009; Mulligan \& Smith 2006; Palmer 2010).

\section{Box 1: Ngapartji Ngapartji}

Ngapartji Ngapartji is a multi-arts program that was run by Big hART (a community cultural development organisation) in the Anangu Pitjantjatjara Yankunytjatjara (APY) Lands of Central Australia (Palmer 2010). The program aimed to: draw out and showcase traditional stories and high-quality art; provide opportunities within communities for increased social interaction, as well as encouraging interaction between Anangu and non-Anangu; build literacy development by promoting use of local languages; and experiment with novel approaches to crime prevention (p.10).

The program employed a range of professional artists-musicians, dancers, theatre specialists, photographers and other visual artists-to run arts workshops in remote communities. These workshops led to the creation of a range of stage performances, as well as

an on-line language course in Pitjantjatjara (the 'Ninti' site), short films (including language lessons and music clips), musical recordings and CDs, a project website, a documentary to be screened on the $A B C$ and 'Memory Basket' resources pack for project participants, organizations and other interested groups (p.11)

The stage shows were taken on tour across remote communities, as well as regional and major urban centres. During the course of rehearsing, developing and performing these productions, young Indigenous people were given opportunities to learn traditional artistic and other knowledge from Elders, thereby building greater intergenerational understanding and empathy, as well as developing self-discipline, resilience and pride in their culture. There is also some evidence that the program contributed to crime reduction by providing a positive focus to divert former offenders from inappropriate activities. For example:

$X$ [a young female with a criminal history] was absolutely amazing and dedicated, worked really well as part of a team of professional performers, contributed many creative ideas to the process, responded really proactively to feedback, criticism, encouragement, and was a delightful addition to the team for her sense of humor and energy. She excelled in her performative role, receiving heaps of positive feedback for her work as shadow-maker, singing and playing the car-part instruments with me and a bit of dancing (p.26).

The presence of a famous Indigenous actor in the stage shows provided positive role models to young people in remote communities, and 'was appreciated by scores of young people and children' (p.25).

The literacy project involved collecting sound recordings, photographs and other cultural information to develop an online Pitjanjatjara language course. By building links to their mother tongue, literacy was enhanced, thereby providing improved links to other Western-based learning at school. For example, one young person involved in filmmaking and media activities subsequently enrolled in a Certificate III media course (p.25).

Several courageous young people used filmmaking to challenge difficult social issues such as petrol sniffing, relaying positive messages and attempting to promote messages intended to alter sniffing behaviour (p.25).

Source: Palmer 2010. 


\section{Facilities as community hubs}

Arts facilities can act as community hubs, which encourage interaction between the generations, different clans, or the Indigenous and non-Indigenous populations. Several studies noted that, in this way, participation in the arts activities generated at these sites can indirectly help to build social cohesion, inclusiveness and support (for example, Cooper et al. 2012:44).

\section{Box 2: Regional arts centres}

The Wirnda Barna Artists art gallery was established in the Upper Murchison region of Western Australia in 2007. In a context of 'normalised racism, social marginalisation of Aboriginal people and few local employment opportunities' (Cooper et al. 2012:8), Wirnda Barna provides a space for established Indigenous artists to meet daily, to paint and to display and sell their work. These senior artists also train and mentor young emerging artists. Equipment is subsidised by the gallery, allowing those on low incomes to paint with higher quality paints and canvases than they might otherwise access.

Cooper et al.'s 2012 evaluation of this project showed that, through the daily interactions, the gallery has facilitated enhanced intergenerational relationships and understanding, the resolution of long-standing family feuds through unhurried dialogue. Furthermore, painting improved the self-image of many Aboriginals by giving them a prized social label (that is, Indigenous artist), and has helped to improve the economic situation of some artists through the sale of paintings. There has been an increase of tourists stopping in the town to visit the art gallery (p.58), and use other commercial services - thereby contributing in part to economic development beyond the Indigenous community. The evaluation '...found that the project had achieved diverse positive social welfare, personal, social, community as well as health and well-being outcomes' (p.8).

\section{Empowerment}

Arts programs can contribute to empowering people to live happy, fulfilling lives. Two particular pathways for empowerment were identified in the studies. These were:

- Taking control in civic spaces: Cooper et al. (2012) found that by learning to run an art gallery, local Indigenous people were empowered not only to take ownership and control of their organisation, but also to participate in broader civic spaces, such as networks of community service providers.

- Changed self-concept: Williams \& Taylor (2004) worked with female prisoners who had also survived sexual assault and showed that 'Interventions such as art, storytelling, music therapy, and group support can foster identity and self-concept change as final outcomes congruent with the goal of empowerment'. 



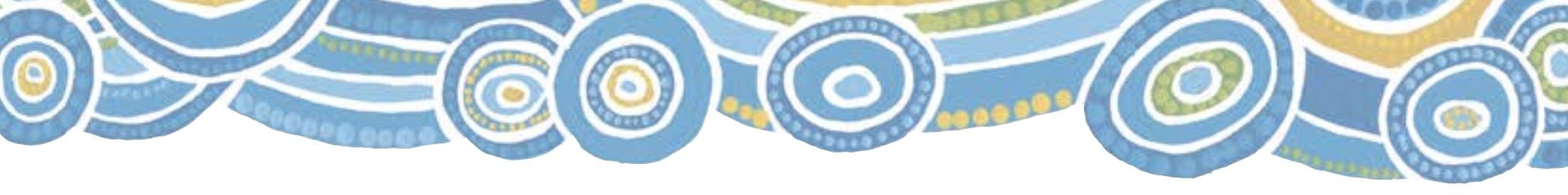

\section{Box 5: Mt Theo Petrol Sniffing Program}

The Mt Theo Petrol Sniffing Program illustrated this clearly (Stojanovski 2010). Although youth were moved away from the Yuendumu township to outstations to participate in learning traditional bush skills, they were able to cease sniffing. However, when they returned to town, they often re-engaged with petrol sniffing, largely due to the lack of other constructive activities. A group of young Warlpiris noticed this pattern and decided to rectify the lack of constructive activities in Yuendumu by starting their own arts and other recreational activities. With other meaningful, fulfilling and enjoyable alternatives, the majority of former sniffers were able to consolidate the changes made on the outstation.

The South Australian Commissioner for Social Inclusion's interviews with delinquent youth documents that they actually repeatedly call for increased arts and sporting activities, so that they do not turn to crime for something to do (SA CSO 2007).

By building greater social interaction and greater understanding of other groups in the community (for example, age or ethnic groups), arts activities can help to reduce the fear of crime in the community, as well as building empathy, which may help to prevent would-be criminals from engaging in wrongdoing (HoRSCATSIA 2011; Palmer 2010). A particularly powerful medium for this is storytelling. One arts organisation's (Big hART) philosophy captures this idea neatly:

It's harder to hurt someone if you've heard their story (Palmer 2010:47).

Some arts projects have found a way to move beyond reducing crime through diversion to challenging the thorny social issues that facilitate the development of criminal behaviours (Palmer 2010:25). By discussing and performing dramatic or musical pieces about petrol sniffing, for example, members of one community were able to begin discussing and dealing with the issue:

In this work they relayed positive and powerful messages about the need to challenge and change certain kinds of behaviour. In this way they moved well beyond crime diversionary work, tackling head on themes of care and responsibility for others (Palmer 2010:25). 


\section{Principles for implementing effective arts programs in Indigenous communities}

The above evidence demonstrates clearly the potential beneficial impacts and outcomes from arts programs in Indigenous communities. The literature reviewed here provides a range of principles that should be considered and incorporated in the development and implementation of a locally relevant and effective arts program. These have been grouped under several themes that emerged. A diagram summarising these principles is also provided (see Figure 2).
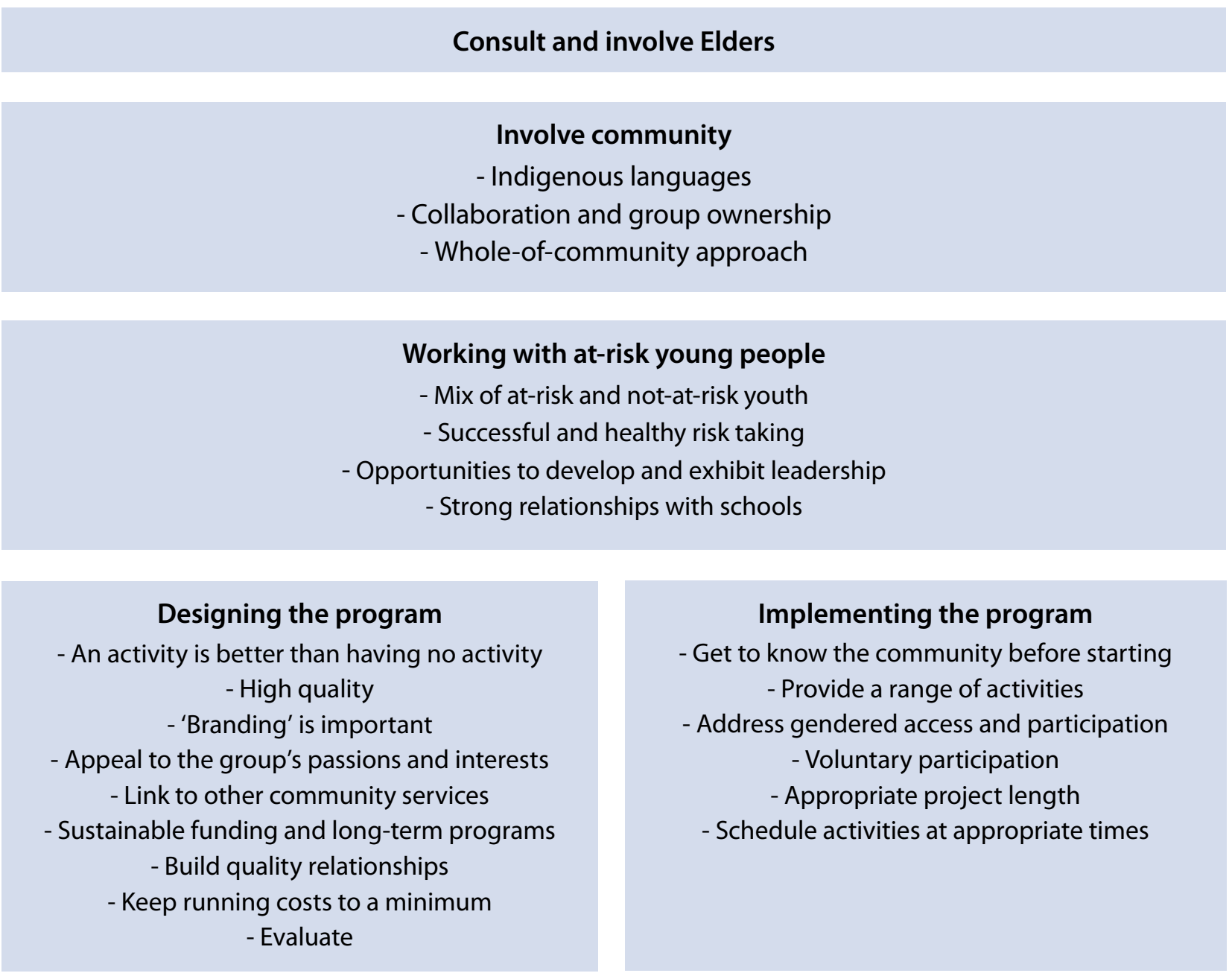

Figure 2: Summary of principles for effective arts programs in Indigenous communities 




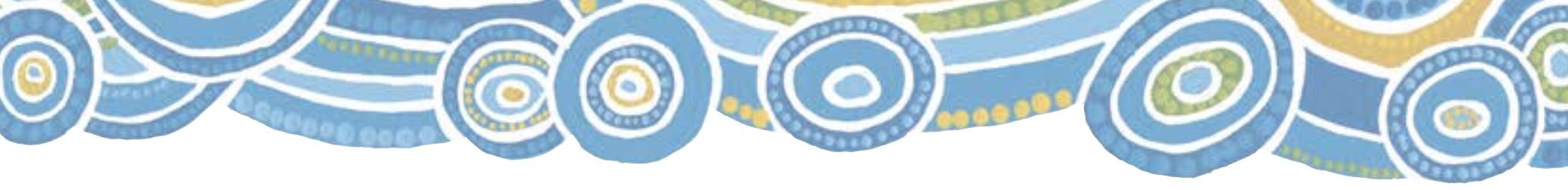

\section{Areas for further research}

Further study in the following two areas would help to improve our knowledge of how the benefits of arts programs help to support healthy Indigenous communities:

- Although evidence suggests that attempting to prove causality between arts programs and positive community outcomes is largely a futile exercise, continuing to build a body of evaluation would provide additional evidence around the nature of these benefits and the mechanisms by which they are produced.

- Longitudinal studies of program outcomes would help to capture and assess the magnitude of those benefits that appear to take longer to form than the average program funding cycle would allow.

\section{Conclusion}

There is a wealth of evidence demonstrating the beneficial effects of participation in arts for supporting healthy Aboriginal and Torres Strait Islander communities. These activities provide a safe place for people to learn new skills, explore and deal with both personal and community trauma and dysfunction, and build social networks. This paper has outlined a range of successful practices, as well as some broad principles for effectively implementing an arts program. It should be noted that, although adhering to these principles is likely to result in effective programs, causal links between an arts program and specific outcomes are almost impossible to demonstrate. Therefore, care should be taken to design specific programs in consultation with the community in which they will be implemented to ensure relevance and the best possible uptake of the program. 


\section{Appendix 1}

The Closing the Gap Clearinghouse Assessed Collection includes summaries of research and evaluations that provide information on what works to overcome Indigenous disadvantage across the seven Council of Australian Governments building block topics.

Table A1 contains a list of selected research and evaluations that were the key pieces of evidence used in this Resource Sheet. The major components are summarised in the Assessed collection.

To view the Assessed collection, visit <http://www.aihw.gov.au/closingthegap/collections/>.

Table A1: Assessed collection items for Supporting healthy communities through arts programs

\begin{tabular}{lll}
\hline Title & Year & Author(s) \\
\hline Indigenous cultural festivals: evaluating impact on community health and wellbeing & 2010 & Phipps P \& Slater L \\
Ngapartji Ngapartji: the consequences of kindness & 2010 & Palmer D \\
Stepping out of the shadows of neglect: towards an understanding of socially applied community & 2006 & Mulligan M \& \\
art in Australia & Smith P \\
Putting people in the picture? The role of the arts in social inclusion & 2005 & Barraket J \\
\hline
\end{tabular}

Table A2 contains a list of Closing the Gap Clearinghouse issues papers and resource sheets related to this resource sheet.

To view the publications, visit <http://www.aihw.gov.au/closingthegap/publications/>.

Table A2: Related Clearinghouse resource sheets and issues papers

\begin{tabular}{lcc}
\hline Title & Year & Author(s) \\
\hline Supporting healthy communities through sports and recreation programs & 2013 & Ware V-A \& \\
Meredith V & Ware V-A \\
Mentoring programs for Indigenous youth at risk & 2013 & Atkinson J \\
Trauma-informed services and trauma-specific care for Indigenous Australian children & 2013 & 2013 \\
Strategies and practices for promoting the social and emotional wellbeing of Aboriginal and & Clearinghouse \\
Torres Strait Islander people & Closing the Gap \\
Strategies to minimise the incidence of suicide and suicidal behaviour & Clearinghouse \\
Parenting in the early years: effectiveness of parenting support programs for Indigenous families & 2012 & Mildon R \& \\
& Polimeni M \\
Early learning programs that promote children's developmental and educational outcomes & 2012 & Harrison LJ, \\
& Goldfeld S, \\
& Metcalfe E \& & Moore T \\
Healthy lifestyle programs for physical activity and nutrition & Closing the Gap \\
Cffective practices for service delivery coordination in Indigenous communities & 2011 \\
\end{tabular}







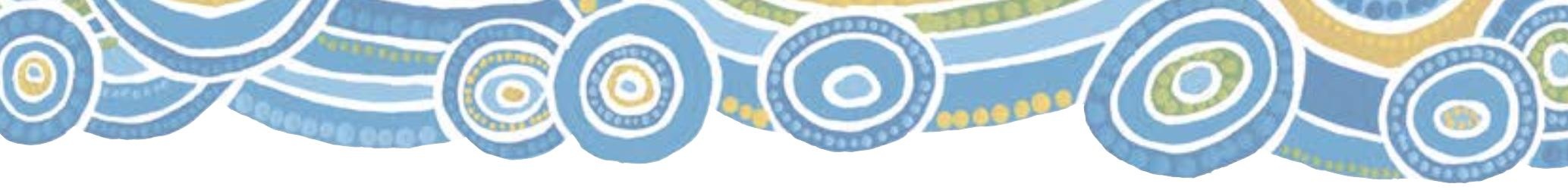

\section{Funding}

The Closing the Gap Clearinghouse is a Council of Australian Government's initiative, jointly funded by all Australian governments. It is being delivered by the Australian Institute of Health and Welfare in collaboration with the Australian Institute of Family Studies.

\section{Suggested citation}

Ware V-A 2014. Supporting healthy communities through arts programs. Resource sheet no. 28. Produced for the Closing the Gap Clearinghouse. Canberra: Australian Institute of Health and Welfare \& Melbourne: Australian Institute of Family Studies.

\section{Copyright}

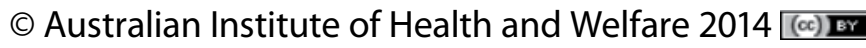

This product, excluding the AlHW logo, Commonwealth Coat of Arms and any material owned by a third party or protected by a trademark, has been released under a Creative Commons BY 3.0 (CC BY 3.0) licence. Excluded material owned by third parties may include, for example, design and layout, images obtained under licence from third parties and signatures. We have made all reasonable efforts to identify and label material owned by third parties.

You may distribute, remix and build upon this work. However, you must attribute the AlHW as the copyright holder of the work in compliance with our attribution policy available at <www.aihw.gov.au/copyright/>. The full terms and conditions of this licence are available at $<$ http://creativecommons.org/licenses/by/3.0/au/>.

Enquiries relating to copyright should be addressed to the Head of the Media and Strategic Engagement Unit, Australian Institute of Health and Welfare, GPO Box 570, Canberra ACT 2601.

ISBN 978-1-74249-534-7

ISSN 2201-845X

Cat. no. IHW 115 